\title{
Multisensory Marketing: Creating New Sustainability Perspective in Hospitality Sector
}

Prarthana Kumar*

\section{Abstract}

Synchronic studies in marketing propose that sensory stimulus, like colour, lighting effects, backdrop music, ambient scents or upholstery's texture, affect consumers' evaluation of the milieu, the wares presented, and affect consumer behavior (e.g., approximate amount spent, time spent at a store). A Customer is frequently attracted towards a brand based on its sensory experience. In toto, the unexpurgated world is experienced through multiple senses. (Lindstrom \& Kotler, 2005). Ingenious brands are discovering means to captivate the entire consumer senses to fortify their brand experience, by amalgamating every sense into the marketing strategy, this approach is called Sensory Marketing. Sensory branding is based on the idea that we are most likely to form, retain and revisit memory when all five senses are engaged. Many companies are discovering that when they engage consumers with multiple sensory touch points - not just the traditional sensory channels of sight or hearing - they can enhance customers' emotional connection with their products and brands. The multisensory strategies seek to go beyond delivering functionality and value to evoking significant personal identification with products. It aims to fill in the lacuna of the conventional marketing. Technology is one of the main factors driving Sensory marketing to success. Sensory Marketing has made its mark in multiple fields like Automobiles, Airlines,

University of Hyderabad, Hyderabad, Andhra Pradesh; prarthanakumar7@gmail.com 
Hospitality, Casinos, Retail stores, Textile, Leather production, Skin Care and Cosmetics at multiple levels.

The following are a few examples for multisensory applications: $74 \%$ of Europeans and $46 \%$ of American recognize the Nokia ringtone (Lindstrom, 2005); Ford has a specific branded aroma since 2000. $27 \%$ of US consumers and $37 \%$ of Europeans consider ford has a distinct smell. (Lindstrom, 2005); United Airlines has adapted a famous composition, George Gershwin's Rhapsody in Blue, and personalized it; Restaurants play slower music as it creates extended dining hours, increasing $29 \%$ of average bill according to an experiment; Heinz launched EZ Squirt Blastin', Green Ketchup in 2001. They sold over 10 million bottles in the first 7 months. That is the highest sales peak in the history of Heinz, all because of a simple color adjustment. This paper deals with use of sensory marketing in technology and the use of technology to make Sensory Marketing successful.

Keywords: Sensory marketing, Technology, Multisensory marketing, Hospitality, Experiential marketing.

\section{Introduction}

Due to environmental dynamism and competitiveness, the struggle for survival and succeeding in business has become more difficult and challenging especially in an age when the consumer has so many choices and suffering loss of a valued customer to a competitor can have significant consequence on profitability and growth. Hence, businesses have shifted their focus from customer acquisition to customer retention. Hence many companies are focusing and directing their energies and efforts toward satisfying the customer.

Customer satisfaction is estimated to be one of the most significant criteria for customer loyalty (Heskett et al., 1994). In the present day, increasing customer satisfaction has emerged as the main point of convergence of many firms to enhance recurring business and benefit from positive word-of-mouth, thus increasing longterm profitability. Marketing and external communications help 
build the brand, but nothing is more powerful than the customers' actual experiences with the service.

\section{Earlier approaches}

The traditional marketing with its marketing mix governed the marketing strategies for a long period, focusing on placement of the product at the best possible price. The possibilities with services are not alike; companies must acclimatize with new marketing strategies to be able to sustain in business. When the services are "invisible", the firm must build a promise and make the clients feel secure. These mutual relations become important, and help the firm to focus on the client's needs instead of the firm's own interests.

\section{Contemporary approaches}

Contemporary approach in marketing is relationship marketing which focuses on the consumer, the business marketing or industrial marketing with focus on an organization or institution and the social marketing with its focus on benefits to the society. This approach attempts to perfect the segmentation strategies employed by the traditional marketing. This enables targeting the market more precisely, and this is labeled as personalized marketing or one-to-one marketing. The culture in the contemporary society is progressively becoming more individualized and experience-based, with copious comparable brands, manufactured goods and services. This is a welcoming initiation towards a fresh marketing epoch. The functional attributes or the product features are not enough to fascinate, sustain the consumer's interest, and persuade the consumers buying behavior or to retain the customers.

Experiential marketing part of the contemporary marketing approach integrates the elements of emotions, logic and general thought processes to bond with the consumers. Experiential marketing aims to establish an association with the customers so that they respond to the product offerings, on the basis of both emotional and rational response levels. Experiential marketing appeals to multiple senses; it aims to tap that special place in the 
consumers' mind which inspires thoughts concerning comfort and pleasure, along with the sense of practicality.

Personal experiences facilitate people to bond with a brand and enable intelligent and informed purchasing decisions. Since experiential marketing bonds with the consumers at copious points, it perfectly suits the contemporary sales and marketing strategies. When done appropriately, it's the most prevailing tool to win brand loyalty.

Sensory marketing is a component of experiential marketing. It uses the customer's experiences lived and feelings in this course. These experiences are not only functional in dimension but also sensorial, emotional, cognitive, behavioural and relational. According to this strategy the customers behave according to their impulses and emotions, more than their reasoning. As reported by Rieunier (2002), "the sensory marketing approach tries to fill in the deficiencies of the 'traditional marketing' which is too rational". Often used in brand-development and tactical marketing efforts, multi-sensory marketing goes beyond just sight and sound (the typical marketing focuses) to create experiences that can be touched, heard, seen, felt, tasted and smelt.

The evolving transformation in the market from the mass marketing concept to relationship marketing approach to sensory marketing which is a vital part of experiential marketing illustrates its significance to firms, consultants, researchers and students to connect to all the human senses deeper than the mass marketing and relationship marketing approaches. Synchronic studies in marketing propose that sensory stimulus, as colour, lighting effects, backdrop music, ambient scents or upholstery's texture, affect the consumer's evaluation of the milieu, the wares presented, and affect the consumer's behavior (e.g., approximate amount spent, time spent at a store). The customer is frequently attracted towards a brand based on its sensory experience. In toto, the unexpurgated world is experienced through multiple senses. (Lindstrom and Kotler, 2005). Our senses link our memory to the right emotions. In this regard, visual and Olfactory senses emerge to be the most influential of all the senses. Multisensory marketing involves several human senses in the marketing process. 
As reported by Kahn, consulting sensory marketing is the purposeful design and deployment of the interaction between the senses in order to stimulate a consumer's relationship with a brand; and to foster a lasting emotional connection that optimizes brand loyalty. The sensory and multisensory marketing approaches have come to stay; very few studies are available regarding the reciprocal effect of backdrop music and ambience scent. Both these senses display that the congruity of sensory stimulus is imperative in stirring up positive customer reactions. Lately the marketers have commenced to theorize the multi-sensory customer experience in the hospitality industry. However, experiential literature sustaining the sensory academic motion is inadequate.

The proposed research adds to the much needed literature on the multi-sensory customer experience in hospitality industry by exploring communications between multiple sensory modalities, like ambience, smell, backdrop music, visual stimulus such as color, lighting and accessibility of tactile information on Cuisines, Life style and Hospitality.

\section{Literature Review of Sensory Marketing}

\section{Visual marketing}

Sight is one of the most seductive senses often dominating the rest; consequently it is the most employed sensory stimulus used in traditional marketing. Studies have revealed that an individual who is exposed to a product would have a preference over similar choices, even though he cannot actually remember seeing the product (Bornstein, 1987).

\section{Auditory marketing}

Together with sight, sound is used as the traditional element in brand-building process (Martin Lindstrom, 2005). As a result of the possibilities that affect store atmosphere and brand image through emotions, having an ambient sound at the point of purchase has, during the last years, become a must (Rieunier, 2009). Music is a powerful tool for evoking emotions; in effect, when listening to music endorphins are released, which generates sensations of pleasure (Gobé, 2001). Because of these positive feelings resulting 
from the endorphins, using sound as an ambiance enhancer can be a very powerful way to bond customers emotionally to a brand (Schmitt \& Simonson, 1997). Music can be used to affect the buying behaviour of consumers in the desired direction (Rieunier, 2009) and can therefore be seen as 'a devise used for constructing brand identity' (Gobé, 2001).

\section{Olfactory marketing}

The sense of smell emotionally affects human beings up to $75 \%$ more than any other sense. Studies illustrate that smell of a product and its sales environment is more essential than sight and sound during the buying process (Harrop, 2009). In 1932 Laird found a positive link between the perceived quality and the use of scent (Bone \& Jantrania, 1992). In fact a brand specific odour is likely to evoke connections to the brand and strengthen the brand identity (Schmitt \& Simonson, 1997).

\section{Gustative marketing}

Taste offers the most specific function of any of the five human senses. In effect, "different tastes are distinguished by various combinations and a more sophisticated sense of smell" (Lindstrom, 2005). A person can be exposed to aroma without including the taste but it is practically impossible to taste something without smelling it (Lindstrom, 2005), something that can be experienced when eating a delicious meal while having a flu. The link between these senses is especially clear when people are asked to describe a brand involving both the taste and the smell aspect. (Lindstrom, 2005). Due to the scientific advancements, the sense of taste is a well mastered and has been exploited by the producer in order to customize the produce according to the regional tastes and preference. For example, in Germany the customers prefer a sweet and salty mix, whereas in Britain softly sour is preferred. (Célier, 2004)

\section{Tactile marketing}

Less marketing consideration is given to the sense of touch, though it engages a greater area compared to any other sense. As a result, the tactile sense improves the customer's brand experience by giving information about the brand's sensory value like the touch 
of the store's door, the sensitivity of walking on floor or the sensation of touching an exclusive leather (Gobé, 2001). The weight of cutleries, the softness of napkin affect the perception of the customer. The touch is a major determinant of the "well-being sensation".

\section{Multisensory applications}

Many studies have been undertaken to discover which type of music suits best different kinds of places: for instance, classical music increases the sensation of quality of a wine cellar (Areni \& Kim, 1993) or a tea house (North \& Hargreaves, 1996); Music also enables "crowd management", it directly influences the customer's time spent at the point of sale. According to two other studies by Roballey \& Ali, 1985, Milliman 1986, faster music tempo pushes the customers to move faster, thereby making them leave earlier. Whereas a slow music played at low volume at a given point sale increases the time and the money spent by the customer. A different study by Smith \& Curnow, 1966 reveals that the customers adjust their walking speed according to the music tempo. Similarly the research also reveals that the customers eat faster and consume lesser with a loud volume and a fast music tempo; Kellogg's invest a huge amount on the auditory stimuli of the brand, apparently testing the crunchiness of cereals at a Danish sound lab to improve the product's "sound quality" and make the auditory appeal as their brand signature. This crunch created a huge difference, and was recognized as the Kellogg's crunch by $45 \%$ of cases, where the box was not present; Proctor \& Gamble (P\&G) was a pioneer to apply the scratch and sniff on its toothpaste packages, and Scentisphere launched Rub'n Smell, a fragrant ink that could be used for printing packages. (Nauth, 2007); In traditional media like newspapers and magazines, scent strips made of microscopic scent-filled balls exude smell to the readers. At present more or less every fashion magazine gives its readers the opportunity to smell perfumes or try a sample of skin care products. Smell has a positive effect on advertising print media. A study by the Dutch firm Senta Aromatic marketing shows $84 \%$ newspaper readers respond to a scented advertisement, which increases their interest in buying the product. Consistent marketing 
of scents through print media can thus raise the consciousness of a brand.

\section{Multisensory practices in airlines}

\section{Singapore Airlines}

Way back in 1973, Singapore Airlines broke through the fence of traditional branding with their Singapore Girl. The Singaporean Girl in 1994 successfully celebrated her twenty-first birthday and was displayed at the famous Madame Tussaud's Museum in London becoming the first brand figure to be given such an honor. They campaigned exclusively on the emotional experience of air travel. The brand emphasized on smoothness and relaxation, and their strategy was to portray themselves as an entertainment company rather than merely just an airlines. The uniforms were of the finest silk. Staff not only looked the brand, but also acted the brand. It included firm directions on how to converse, move around and serve food in the cabin. Singapore airlines clearly aimed to create a great sensory brand experience which focused on much more than just what the passengers saw and heard; the announcements made by the captain also were meticulously scripted by an advertising agency. The Singapore airline's branding reached the peak during the late 1990s when it introduced Stefan Floridian Water. Stefan Floridian Water was an aroma specifically designed for Singapore Airlines. This aroma is patented and ever since is a unique distinct trademark of Singapore Airlines. (Lindstrom, 2005).

\section{Korean Airlines}

Korean Airlines has been introducing a lot of aesthetic endeavours to appeal to multiple senses through the visual medium of television. Most of the advertisement appears to be a luxury fashion ad - only at the end, the glimpse of a Korean Air jumbo and an attractive flight attendant for a few seconds are seen.

\section{United Airlines}

United Airlines adapted a very famous composition, by George Gershwin called Rhapsody in Blue, and personalised it. The Airline 
cleverly used this theme in most of the advertisements, by modifying the composition to keep it relevant to the content.

\section{Multisensory applications in hospitality sector}

The most famous technique adopted by super markets in Northern Europe is that they used olfactory marketing for their bakeries using artificial aroma to appeal to customers on the street or subways, which led to increased traffic to their stores. Sight is one of the most important senses used in the food-industry; vision gives the first impression of the quality, of the product as for the environment. Senses progressively appeared in the marketer's strategy. Sensory marketing is a complex concept, dealing with the 'unconscious' of the customer: their perceptions, feelings, emotions, tastes and preferences. This approach necessarily allows controlling the atmospheric dynamics. During the 1950's, brands primarily focused on the product's colours, its designs and its advertisements as most of the promotion were through posters. For example, the design and colour of the Coca-Cola bottle, reminds the consumer the form of a woman; The Starwood Hotels and Sheraton Hotels introduced the fragrance of Fig, Clove and Jasmine in their hotels. (Bell, 2006); The Westin and Four points introduced a white tea flavour and cinnamon respectively. (Bell, 2006); 5+ Sensotel stimulates all the senses using light, sound and scent to suit the moods. (Bell, 2006). Restaurants play softer, slower music as it creates extended dining hours, increasing $29 \%$ of the average bill according to an experiment. A Mexican lodge in Santa Fe, uses scent of piñon and sage burning with the live smells of burning wood and heated masonry, cleansed with the sentiment of iced snow fall, outside: sandalwood, frankincense, the back corridors of Marrakhesh and the entry into another world of private containment, spices reeling out of the kitchen, melted sugars softening the edge. "The idea was to do a scent of old books in a wonderful library, old paper, leather, wooden shelves"; this olfactory logo, a signature fragrance for Le Méridien, was made by Le Labo a custom perfume designer. A spa combines heat treatment with a unique shower experience, using these options: Rain - refreshing with a cold rain shower, Head - feel the warm water all over body as it is soothing, Full Body Massage - this is an adjustable energizing vertical shower which pleasantly massages 
and vitalizes, Kneipp Hose - to enjoy an invigorating body spray, Fresh - cold, refreshing mist sprayed all over the body. This is a tingling, refreshing and revitalizing experience of Tropical Rain where one surrenders oneself to the tropical rain, drenched in huge droplets from the shower head.

\section{Conclusion}

Sensory marketing is the future of marketing and is exploding. Technology very tactfully and rightly makes sensory integration more practical and affordable for the marketers looking out for logical new frontiers; as business broadens the horizon of their products, offering the sensory marketing strategies enables the customers to try out a new product before buying it. The sensory cues of auditory and olfactory senses facilitate companies to build superior emotional connections to their brands. Prefect use of the Auditory sense is the easiest way to tap the market for a brand looking forward to try out sensory marketing. The logic is simple; the more the accessibility you provide, the greater is your chance to connect to the customers. The senses wholly influence our emotions and decision-making, touch, smell, taste, sound, and the look of a product - all play a vital role in our perceptions, attitudes and consumption of the product. Understanding the roles played by these offers a valuable lead in today's marketplace. Though the stimulation of the senses is of vital importance in today's marketing, the use of specific sense as a marketing technique has not been uniformly developed.

\section{Sensory marketing as a promotional advantage}

Sensory marketing can be used by firms as a promotional advantage for several reasons like: a) It endeavours to attract people b) It creates brand preferences and stimulating the unconscious sense of the consumer and c) It the gives companies a cutting edge - "something more" than its competition.

\section{Business implications of sensory marketing}

The concept of Multisensory marketing would become much vital to marketing in the coming years, and actually might grow to be a 
cost of admission into a few industries or product markets. The rising older generation consider a few small indulgences a significant part of their routine life; but this generation would require a more effective sensory stimuli. Countries like Japan, India, and Thailand have a longstanding rich culture and traditions of integrating the five senses. In future, more US firms will loan for flavours and look for globally appealing sensory cues. At the same time, global companies will focus on local taste and preferences using their multisensory to fit the countries. Some will find this a deterrent to applying multisensory marketing in all but the most affluent markets.

\section{References}

Adrian, P., \& Patrick, M. (2000). The role of electronic commerce in creating virtual tourism destination marketing organisations. International Journal of Contemporary Hospitality Management.

Alistair, W. (2006). Tourism and hospitality marketing: fantasy, feeling and fun. International Journal of Contemporary Hospitality Management, 18(6).

Areni, C., \& Kim, D. (1993). The influence of background music on shopping behavior, classical versus top-forty music in a wine store. Advances in Consumer Research, 20, 336-340. doi:10.1177/ 0013916503254749

Baird, S. (2009, March 26). Touchy trademarks. Retrieved from http://www.duetsblog.com/2009/03/articles/trademarks/touchytrademarks/

Bell, S. (2006). Future sense: Defining brands through scent. Retrieved from http://www.wppindia.in/ / media/SharedWPP/Marketing\%20Insi ghts/Reports\%20and\%20Studies/coley_futuresense.pdf

Bone, P. F., \& Jantrania, S. (1992). Olfaction as a cue for product quality. Marketing Letters, 3(3), 289-296.

Bornstein, M. H. (1987). Perceptual categories in vision and audition. In S. Harnad (Ed.), Categorical Perception: The groundwork of cognition. Cambridge: Cambridge University Press.

Celier, P. (2004, April 2). Le marketing sensorial. Retrieved from http:// cpa.enset-media.ac.ma/marketing_sensoriel.htm.Gobé, M. (2001). 
Emotional branding: the new paradigm for connecting brands to people. New York: Allworth Press.

Hairong, L., Terry, D., \& Frank, B. (2002). Impact of advertising on product knowledge, brand attitude and purchase intention: the mediating role of presence. Journal of Advertising.

Hulten, B., Niklas, B., \& Marcus, V. D. (2009). Sensory marketing. New York: Palgrave Macmillan.

Jha S.M., (2000).Services Marketing. Himalaya Publishing House.

Joann, P., \& Terry L, C. (2003). Individual differences in haptic information processing: the 'need for touch' scale. Journal of Consumer Research, 30. doi:10.1086/378619

Krishna , A., \& Ryan, E. (2010). The effects of advertising copy on sensory thoughts and taste. Journal of Consumer Research, 36. doi: 10.1086/605327.

Krishna, A. (2009). Sensory marketing: Research on the sensuality of products. Psychology Press.

Kotler, P. (2006). Marketing management millennium edition. (10 ed.). Prentice-Hall, Inc.

Lowery, T. M. (Ed.), Brick \& mortar shopping in the 21st Century (Advertising and consumer psychology)Mahwah: Lawrence Erlbaum.

Laura, O. (2001, July). Some notes on semiotics and sensory marketing. Retrieved from http:/ / www.marketingsemiotics.com/pdf/semiotics.pdf

Laurie A, B., \& Alvin C, B. (1997). Effects of print ad pictures and copy containing instructions to imagine on mental imagery that mediates attitudes. Journal of Advertising, 26(3), 33-44.

Lindstrom, M. (2005). Broad sensory branding. Journal of Product $\mathcal{E}$ Brand Management, 14(2), 84-87.

Lindstrom, M. (2005). Sensory branding: It makes (five) senses, brand child and brand sense. New York: Free Press.

Milliman, R. (1986). The influence of ancienne music on the behavior of restaurant patrons. Journal of Consumer Research, 12, 286-289.

Nauth, K. (2007, November 18). The future of multisensory marketing. Retrieved from http://www.prweb.com/releases/2007/11/ prweb570225.htm 
North A. C., Hargreaves, D. J. (1996). The effects of music on responses to a dining area. Journal of Environnemental Psychology, 16, 55-64. doi :10.1006/jevp.1996.0005

Rieunier, S. (2002). Le marketing sensoriel du point de vente. Recherche et Applications en Marketing, 17(4).

Rieunier, S. (2009). Le marketing sensoriel du point de vente: Créer et gérer l'ambiancedes lieux commerciaux. Paris: Dunod.

Roballey, T. C. (1985). The effect of music on eating behavior. Bulletin of the Psychonomic Society , 23, 221-222.

Schmitt Bernd , H., \& Simonson, A. (1997). Marketing aesthetics: The strategic management of brands, identity, and image. New York: The Fress Press.

Smith, P., \& Curnow, R. (1966). Arousal hypothesis and the effects of music on purchasing behaviour. Journal of Applied Psychology, 50, 255286.

Stephens, J. (2007). How to put the sense of olfaction into marketing action. ABA Bank Marketing.

Stephens, Jeff. (2007). Setting the tone. ABA Bank Marketing. 